\title{
Bernard Hours, Histoire des ordres religieux
}

Paris, Presses universitaires de France, coll. « Que sais-je ?», 2012, 127 p.

\section{Bertrand Marceau}

\section{(2) OpenEdition}

Journals

Édition électronique

URL : http://journals.openedition.org/assr/25518

DOI : $10.4000 /$ assr.25518

ISSN : 1777-5825

Éditeur

Éditions de l'EHESS

Édition imprimée

Date de publication : 30 décembre 2013

Pagination : 218

ISSN : 0335-5985

Référence électronique

Bertrand Marceau, "Bernard Hours, Histoire des ordres religieux ", Archives de sciences sociales des religions [En ligne], 164 | 2013, mis en ligne le 04 mars 2014, consulté le 21 septembre 2020. URL http://journals.openedition.org/assr/25518 ; DOI : https://doi.org/10.4000/assr.25518

Ce document a été généré automatiquement le 21 septembre 2020

(c) Archives de sciences sociales des religions 


\section{Bernard Hours, Histoire des ordres religieux}

Paris, Presses universitaires de France, coll. « Que sais-je ?», 2012, 127 p.

Bertrand Marceau

\section{RÉFÉRENCE}

Bernard Hours, Histoire des ordres religieux, Paris, Presses universitaires de France, coll. «Que sais-je ?», 2012, 127 p. 
1 Dans l'histoire du christianisme, la recherche de la perfection évangélique a produit des formes de vie originales et éloignées du siècle. En tant que partie de l'Église reconnue et sanctionnée légalement par celle-ci, les moines puis les ordres religieux ont acquis, depuis leur naissance au $\mathrm{IV}^{\mathrm{e}}$ siècle sur les rives de la Méditerranée orientale, une renommée qui a suscité des synthèses anciennes et récentes: l'ordre désigne d'abord un mode de vie, puis l'association d'établissements religieux pratiquant ce même mode de vie. Reprenant en abrégé un titre qui est en usage depuis la fin du $\mathrm{XVII}^{\mathrm{e}}$ siècle au moins (J. Hermant, Histoire des ordres religieux et des congrégations régulières et séculières de l'Église. Avec l'éloge et la vie en abrégé de leurs saints patriarches,

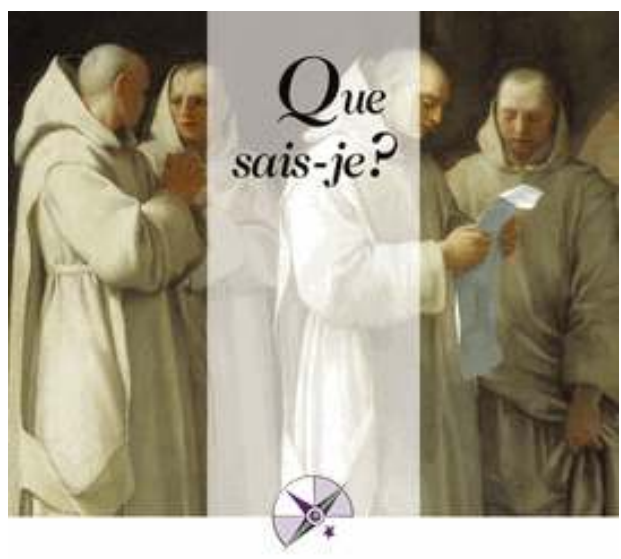

\section{HISTOIRE DES ORDRES RELIGIEUX}

Bernard Hours $\&$ de ceux qui y ont mis la réforme, t. I, Rouen, Chez Jean-Baptiste Besongne, 1710, 428-IV p. Une première édition a paru en 1697 sous un titre légèrement différent) et succédant à Jacques Dubois, mort en 1991, dans la même collection "Que sais-je ? » (J. Dubois, Les ordres monastiques, Paris, 1985, $7^{\mathrm{e}}$ éd. 2005, 128 p. Le titre de dom Dubois peut lui-même se rapprocher d'un classique de l'historiographie monastique du XVIII siècle, rédigé par le P. Pierre Hélyot et continué par le P. Maximilien Bullot, la volumineuse Histoire des ordres monastiques religieux et militaires et des congrégations séculières de l'un et l'autre sexe, qui ont été établies jusqu'à présent, Paris, 1714-1719, 8 vol.), Bernard Hours relève dans son Histoire des ordres religieux le défi de réécrire et d'actualiser dans un mince ouvrage clair et nuancé l'histoire du monachisme catholique. Bien que ce dernier n'épuise pas toutes les formes de monachisme, ni dans ni en dehors du christianisme, l'auteur explique fort bien ce choix, déjà large au vu de la chronologie longue. La définition du moine comme un renonçant séparé des voies sociales ordinaires permet d'écarter l'étymologie parfois trompeuse : celui-ci ne vit pas toujours dans la solitude, bien plutôt la vie communautaire ou cénobitique domine-telle dans l'histoire du monachisme catholique. Sur le modèle des pratiques érémitiques des pères du Désert, et notamment celles de saint Antoine en Égypte dans la première moitié $\mathrm{du} \mathrm{IV}^{\mathrm{e}}$ siècle, se développe en Italie, en Gaule ou dans la péninsule ibérique un premier monachisme à partir de fondements ascétiques (virginité, pauvreté, prière ou encore jeûne).

2 La floraison des modes de vie régulière en Occident appelle la rédaction de règles, afin de fixer le sens et le cadre communautaires. Certaines sont appelées à un succès durable, comme la règle de saint Benoît, formant ce que l'auteur appelle « le paradigme bénédictin », qui « constitua la référence majeure de l'univers monastique » (p. 18) de la chrétienté médiévale. La liste des communautés prestigieuses influencées directement ou non par la règle bénédictine est longue, des premiers essais où elle n'occupe qu'une place parmi d'autres, comme à Luxeuil ou à Bobbio, jusqu'aux foyers 
majeurs du Mont-Cassin (718), de Cluny (910) ou de Gorze (933). Composé de plus de mille établissements, l'Ecclesia cluniacensis achève de constituer son puissant réseau quand la concurrence, sur le même modèle bénédictin, apparaît avec la fondation de Cîteaux (1098). Fort de plus de 350 maisons au milieu du XII ${ }^{\mathrm{e}}$ siècle et de plus de 700 monastères à la fin du $\mathrm{xIII}^{\mathrm{e}}$ siècle, l'ordre cistercien offre une relecture de la règle bénédictine, à la recherche de la pureté originelle. L'importance du charisme du fondateur et le renouveau de l'érémitisme produisent concomitamment des formes intermédiaires de vie entre la solitude et la communauté, comme celle de Bruno de Cologne à la Chartreuse (1084). Le milieu régulier ne demeure pas non plus indifférent au mouvement des croisades intérieures et extérieures, donnant naissance aux ordres hospitaliers et militaires. Dans la mesure où leur succès grandissant donne richesse et puissance aux ordres monastiques, une réaction se produit avec la fondation des ordres non rentés. Certains de ces premiers mouvements sont hétérodoxes, mais les Franciscains et les Dominicains illustrent respectivement la pauvreté et l'orthodoxie des nouveaux ordres mendiants au xIII ${ }^{\mathrm{e}}$ siècle. Au service de la prédication, les mendiants actifs dans le siècle se séparent de la voie contemplative : «Ainsi à partir du milieu du $\mathrm{xIII}^{\mathrm{e}}$ siècle, la vie régulière s'organisa selon deux polarités non exclusives » (p. 42).

3 Après des pages mesurées et bienvenues sur "la thématique de la décadence " (p. 46-50), Bernard Hours marque les avancées de la fin du Moyen Âge et du début de l'époque moderne : revalorisation du travail intellectuel malgré les polémiques, progrès de l'observance chez les Mineurs, ou extension de la devotio moderna sans structures bien établies, le tout préparant «un nouvel âge des réguliers" dans la première modernité marquée par les tensions eschatologiques (p. 61-80). De cette période riche et contradictoire, B. Hours fait ressortir l'intérêt en partant de la qualité de moine augustinien de Luther. La réforme se déplace de celle d'un ordre à celle de l'Église et rencontre le soutien de nombreux réguliers. Cette ébullition prélude tout à la fois à la fermeture et à la sécularisation partielle ou complète des abbayes dans l'Empire, en Angleterre ou en Scandinavie, mais aussi à la rénovation des chanoines réguliers et des religieux bénédictins, cisterciens ou mendiants en France, dans les péninsules ibérique et italienne, ou dans les pays germaniques demeurés catholiques. Lié à la confessionnalisation, ce double mouvement occasionne là des retraits durables de la vie régulière et produit ici à l'inverse des créations pérennes comme la Compagnie de Jésus, société de prêtres unis par des vœux et formant ainsi un ordre de clercs. Bien caractérisé comme ambivalent (p. 86-91), le Siècle des Lumières forme ensuite une période charnière. Se développent d'une part une critique du monachisme qui n'est pas sans rappeler la virulence des polémiques du $\mathrm{XVI}^{\mathrm{e}}$ siècle, et qui se fonde à la fois sur la satire des philosophes et sur la politique de restriction de plusieurs États catholiques, et d'autre part une série de mutations et de renouveaux qui préservent les traditions régulières et préparent les communautés religieuses à l'approfondissement de la sécularisation. La sociologie du recrutement des congrégations féminines, notamment hospitalières, offre en ce sens un exemple de dynamisme. Se comprennent alors les racines de l'essor du monde des réguliers au XIX jusqu'à la moitié du $\mathrm{xx}^{\mathrm{e}}$ siècle: "Jamais les religieux n'ont été aussi nombreux qu'au début des années 1950, en proportion du clergé comme en valeur absolue » (p. 92). Tombés à quelques centaines vers 1815 , les moines bénédictins sont presque 1600 en 1850 et 6000 en 1900 ; supprimés ou bannis à plusieurs reprises, les Jésuites quant à eux sont 2000 en 1820 et 17000 en 1914. Si l'on ajoute les fondations nouvelles, masculines comme les Salésiens 
ou féminines comme les Petites Sœurs des Pauvres, le phénomène régulier marque à nouveau plusieurs nations catholiques. Contrôlés plus étroitement par Rome, qui veut encadrer et centraliser le gouvernement des établissements, les religieux participent pleinement aux évolutions du catholicisme contemporain, représentés par des profès célèbres (Thomas Merton ou Jean-Baptiste Chautard) ou des théologiens réputés (Henri de Lubac). Face à la modernisation technique et à certaines propositions irréfragables du monde extérieur, les ordres religieux sont devenus protéiformes et n'ont pas achevé encore leur mutation.

4 Cet opuscule, qui n'oublie pas le versant féminin de la vie régulière (vierges et moniales des premiers siècles, béguines nées à la fin $\mathrm{du}_{\mathrm{XII}}^{\mathrm{e}}$ siècle, ou visitandines au début du XVII ${ }^{e}$ siècle), qui donne une bibliographie brève, mais à jour, ainsi qu'un petit glossaire, forme en conséquence une introduction solide à l'histoire monastique en Occident, intégrant finement les derniers apports de l'historiographie. Les esprits chagrins regretteront certes l'absence de tel ou tel point particulier, puisque l'on ne trouve pas, par exemple, de long développement sur l'Hôpital du Saint-Esprit in Sassia de Rome, transformé en ordre mixte au début du XIII ${ }^{\mathrm{e}}$ siècle; les autres apprécieront dans ce volume un bel exemple de synthèse utile à l'historien néophyte ou confirmé. 